Research Article

$\mathrm{J}$ Exp Clin Med

2021; 38(4): 496-503

doi: $10.52142 /$ omujecm.38.4.18

\title{
How have the obstetricians and gynecologists struggled in the clinics during the COVID-19 pandemic?
}

\author{
Deha Denizhan KESKİN ${ }^{1}$, Seda KESKİN ${ }^{1, *}$ ib, Sedat BOSTAN 2 (i) \\ ${ }^{1}$ Department of Obstetrics and Gynecology, Faculty of Medicine, Ordu University, Ordu, Turkey \\ ${ }^{2}$ Department of Health Management, Faculty of Health Sciences, Ordu University, Ordu, Turkey
}

\begin{abstract}
Received: 14.03 .2021
Accepted/Published Online: 27.03 .2021

$\bullet$

Final Version: 30.08 .2021

Abstract

As all branches of the medicine, the obstetrical and gynecological clinical approach has been greatly affected by the pandemic. In our study, we aimed to reveal the effect of the pandemic on current obstetrics and gynecologic clinical approach and urgency/semi-urgency evaluations of physicians related with both obstetrical and gynecological cases. The obstetricians in Turkey from different hospitals and clinics have completed our online questionnaire-based survey using 'docs.google.com'. The survey questionnaire was created in three sections: Demographic, occupational analysis and thoughts about outbreak, clinical approach scale and clinical urgency scale. SPSS 22 program was used to analyze the validity and reliability of the scales. The outbreak has affected the clinical approach according to our study. The effect degree was 3.79, 3.15, 3.72 respectively at clinical effect, clinical functioning and struggle and prevention. The specialists regardless of the year in the occupation were more affected than research assistants in terms of clinical effect $(p=0.017)$ and also postponed obstetrical $(p=0.000)$ and gynecological $(\mathrm{p}=0.000)$ conditions more frequently. As the effect of the pandemic on clinical functioning increases, the delay of gynecological cases increases. With the postponement of obstetrics cases, the probability of delaying gynecological cases increases. In the current study, it was concluded that the pandemic has affected the clinical approach in obstetrics and gynecology clinics. We think that the study will help in determining our approach to obstetrical and gynecological cases in the future. Scenarios should be made patient-centered without neglecting the burden and possible damages on healthcare professionals.
\end{abstract}

Keywords: clinical approach, clinical effect, clinical urgency, gynecology, obstetrics, pandemic

\section{Introduction}

In late 2019, hospitals in Hubei province of China began reporting unusual cases of pneumonia among Huanan seafood market employees and visitors $(1,2)$. As the cases spread throughout the whole of Wuhan city in a short time, the World Health Organization (WHO) confirmed the public health problem on 31 December 2019 (3). In January 2020 as a result of examining the pneumonia cases, scientists achieved to isolate a novel beta coronavirus that $85 \%$ similarity to a bat SARS-CoV genome $(4,5)$. Because of the genomic similarity with SARS-CoV, the virus has been named SARS-CoV-2 and the disease has been called COVID19 (3, 5, 6). By 11 March 2020 it was described as a pandemic because of the 118.223 confirmed cases and 4.291 deaths in 114 countries $(3,7,8)$.

As it all branches of medicine, obstetricians and gynecologists delayed semi-urgent and non-urgent surgeries and decreased acceptance of patients and also extended the follow-up frequencies of some medical conditions through committee opinions of the concerned societies $(9,10)$. With the widespread of the outbreak, in the frame of precautions taken by Turkish Ministry of Health, all healthcare workers decreased elective cases and surgeries both in the state and private hospitals (8).

The obstetrical and gynecological clinical approach had been greatly affected by the pandemic. The obstetrical and gynecology practice shows both heavy patient and surgery burden. The surgical practice of obstetrics and gynecology includes deferrable, semi-urgent and urgent operations. The obstetrical clinical approach is more necessary that they require more stringent examination follow-up and the processes such as delivery cannot be postponed. Furthermore, disruptions that occur especially in the follow-up of high-risk pregnancies can lead to fetal and maternal complications (11). Many benign gynecologic cases are elective and can be delayed until the pandemic is brought under control, but the diagnosis and treatment processes of gynecological malignancies cannot be delayed for an extended period ( 9 , 10).

In our study, we aimed to reveal the effect of pandemic on current obstetric and gynecological clinical approach and urgency evaluations of physicians on obstetrical and gynecological cases. 


\section{Materials and methods}

One hundred and twenty-two obstetricians in Turkey from different hospitals and clinics have completed our online questionnaire-based survey using 'docs.google.com'. Volunteer participants were invited through email and social media messages. Since the researchers do not have the opportunity to determine the participants in the digital environment, sampling management is chosen as simple random sampling method. Also, the reason for choosing the simple random sampling method is that it enables easier, cheaper and faster data collection than other sampling techniques.

The questionnaire was published online on April 18, 2020 and was available online for two weeks. Outbreak and dense business of obstetricians were the limitations of the data collection. The survey was anonymized by the name and place of work. Ethical approval was required from the ethics committee of Ordu University Medical Faculty, Ordu.

The survey questionnaire was created in three sections. In the first section, demographic, occupational analysis and clinicians' thoughts about outbreak was questioned. Eleven questions were asked to participants, six of which were openended. The details of the first survey section have been given on table 1 .

Table 1. Demographic, occupational analysis and clinicians' thoughts about outbreak

\section{Part I of the survey}

Demographic questions

Age

Year in professional

Gender

Type of hospital

Professional title

Thoughts about outbreak

Do you work in pandemic hospital?

Have you encountered Covid-19 suspected patient?

Have you encountered a patient diagnosed with Covid-19?

What do you think is the most important point in the Covid-19 struggle?

Have you been tested related to Covid-19?

What is your opinion about applying Covid-19 test to healthcare professionals?

In the second section, clinical approach scale was interrogated. The clinical approach scale was conducted as three part including clinical effect (six multiple-choice and two open-ended questions), clinical functioning (ten multiplechoice and two open-ended questions), struggle and prevention (four multiple-choice questions). These questions of the scale querying how the clinical approach have been affected by the pandemic. The details of the second survey section have been given on table 2 .

And the last section of the survey contains the clinical urgency scale that consist nine obstetrics and thirteen gynecologic conditions. The scale answers which obstetrical or gynecologic conditions are described as urgent or deferrable by the surgeon. Both the clinical approach and the clinical urgency scales were prepared by taking the suggestions of leading academicians, associations and societies. As a result, these two scales were used to investigate the effects of pandemic on clinical activities and surgeons' sense of urgency. The details of the third survey section have been given on table 3 .

SPSS 22 program was used to analyze the validity and reliability of the scales. Factor analysis was conducted to understand the construct validity of the items of the scale. The clinical approach scale was firstly prepared as 24 questions. However, as a result of factor analysis, four expressions were excluded from the statistics because the factor loads were low or incompatible. As a result, the clinical activity scale was validated as 20 statements.

The Kaiser-Meyer-Olkin (KMO) test was performed for the sample number and it was found to be 0.664 . In addition, Barlett's sphericity test, which was used to evaluate the scale's suitability for factor analysis, was found to be significant at the level of 0.001 (Approx. Chi-Square: 720.420/df:190/sig:0.000). In order to dimension the question items in the scale, 'Verimax' rotation was applied with the 'principal components' method. The clinical approach scale items were found to have factor loads between 0.404 and 0.788. The scale's results were conducted on a five-point likert scale and gathered around three factors. These factors were named as; clinical effect (6 expressions), clinical functioning (10 expressions), struggle and prevention (4 expressions) factors. The variance explanation level of the factors in the scale was calculated as $42.9 \%$. Cronbach's Alpha coefficient was calculated as 0.670 for the reliability analysis of the clinical activity scale. This value was found to be confident at the acceptable level.

The clinical urgency scale was consisted of 22 questions that also conducted on a five-point likert scale and gathered around two factors. These factors were named as; obstetrics (9 expressions) and gynecologic (13 expressions). Factor loadings of the expressions in the scale vary between 374 and 885. Kaiser-Meyer-Olkin (KMO) test was performed for the sample number and it was found to be 0.789. Barlett's sphericity test was found to be significant at the level of 0.001 (Approx. Chi-Square: 1804.662/df:231/sig:0.000). In order to dimension the question items in the scale, 'Verimax' rotation was applied with the 'principal components' method. The scale was collected under two factors. The variance explanation level of the factors in the scale was calculated as $48 \%$. Cronbach's Alpha coefficient was calculated as 0.90 for the reliability analysis of the clinical activity scale. And this value was found to be perfectly reliable.

In the research, whether demographic and occupational 
characteristics of obstetricians and gynecologists have a differentiating effect on the factors of the scales in the survey was investigated by $\mathrm{t}$ and Anova tests.

\section{Results}

One hundred and twenty-two obstetricians and gynecologists participated in the study. The survey was consisted of three sections.

\subsection{Demographic, occupational analysis and thoughts about outbreak}

According to the results, $54.9 \%$ of the participants were women, $45.9 \%$ were in the age groups of 39 and under; $23.8 \%$ of the clinicians continued their education as research assistant. It was determined that $36.9 \%$ of the participants worked in state hospitals, $32.8 \%$ in university hospitals, and the others in private hospitals or private clinics. According to the results, $62.3 \%$ of the physicians stated that they have been working in a pandemic hospital and 6.6\% stated that they have accepted suspicious patients even though they do not work in a pandemic hospital. $72.1 \%$ of the respondents confirmed that they had contact with patients with suspected COVID-19, 37.7\% confirmed that they had contact with patients with the diagnosis of COVID-19. While $34.1 \%$ of the respondents stated that they had the COVID-19 test, the results of the five participants' COVID-19 test were positive. The details about the demographic, occupational analysis and clinicians' thoughts about outbreak have given in table 1 .

\subsection{The clinical approaches scale in Obstetrics and Gynaecology}

The clinical approach scale was designed to show how the surgeons' clinical approaches were affected in the pandemic. It was concluded that the pandemic process has affected the clinical approach. The effect degree was 3.79, 3.15, 3.72 respectively at clinical effect, clinical functioning and struggle and prevention. The results of the clinical approach scale have been presented in table 2 .

In open-ended questions about the clinical effect and functioning, $34.5 \%$ of the doctors who stated that they routinely received a separate consent form from the patients, but only $3.3 \%$ requested COVID-19 test in patients who needed hospitalization. In the future after the pandemic; 50\% of physicians believe that online scientific congresses will be common and also $52.4 \%$ of them stated that online treatments will become more common.

\subsection{The clinical urgency scale in Obstetrics and Gynaecology}

The clinical urgency scale was designed to show how the surgeons' thoughts of urgency were affected in the pandemic. The scale was designed to answer which obstetrical and gynecological conditions was described as can be postponed regardless of time $(<2.5)$ or can be postponed for a while $(2.5$ $3.5)$ and cannot be deferrable so urgent $(>3.5)$ according to the surgeon. In order to understand the details of the findings, the arithmetic means and frequency distributions of the clinical urgency scale have been shown in the table 3 .

\subsection{Statistical analysis}

In the research, whether demographic and occupational characteristics of obstetricians and gynecologists have a differentiating effect on the factors of the scales in the survey was investigated by $\mathrm{t}$ and Anova tests. According to the results; it was observed that the year in the occupation had a statistically significant effect on both scales (clinical approach scale and the clinical urgency scale in obstetrics and gynecology). The clinicians who have been working as specialist for 6-10 years were more affected than research assistants in terms of clinical effect $(\mathrm{p}=0.008)$. Besides it was shown that physicians who have been working as specialist for 6-10 years have delayed both obstetrical $(p=0.002)$ and gynecological $(\mathrm{p}=0.000)$ cases more than research assistants. Generally, the specialists regardless of the year in the occupation were more affected than research assistants in terms of clinical effect $(\mathrm{p}=0.017)$ and also postponed obstetrical $(p=0.000)$ and gynecological $(p=0.000)$ conditions more frequently. It was observed that the specialists were more sensitive about using protective equipment and besides, due to their professional experience, they postponed both obstetrical and gynecological cases more than research assistants. It has been observed that the type of hospital has created a significant difference on clinical functioning $(\mathrm{p}=0.021)$. Doctors who have been working in the state hospitals were more affected than the doctors working in private clinics in terms of clinical functioning $(p=0.021)$. Also, it was observed that the clinicians that working in private clinics postpone gynecological situations more than the physicians working in the state and university hospitals $(p=0.005)$. We think that private clinics have less affected in terms of clinical functioning than state hospitals due to their low out-patient load. Despite the effect in clinical functioning, it was observed that they postponed gynecological cases more due to the fact that they gave more importance to the followup of obstetric cases.

The clinical functioning of female physicians was more affected $(p=0.017)$. The clinical functioning $(p=0.026)$ of physicians working in the pandemic hospital were more affected, and it was also observed that they tend to delay gynecological $(\mathrm{p}=0.001)$ cases more. It was an expected result that the clinical procedures of the physicians working in the pandemic hospital would be affected more. We think that postponing the gynecological cases more is a measure to reduce the patient load in pandemics. The relationship between the factors of both scales was examined by Pearson correlation analysis and the results are given in table 4. A linear weak correlation was found between the clinical effect and clinical functioning at the level of $p=0.05$ error $(0.210)$. It has been concluded that as the clinical effect degree of the pandemic increases, changes in clinical functioning would increase. 
Table 2. The clinical approach scale in obstetrics and gynecology
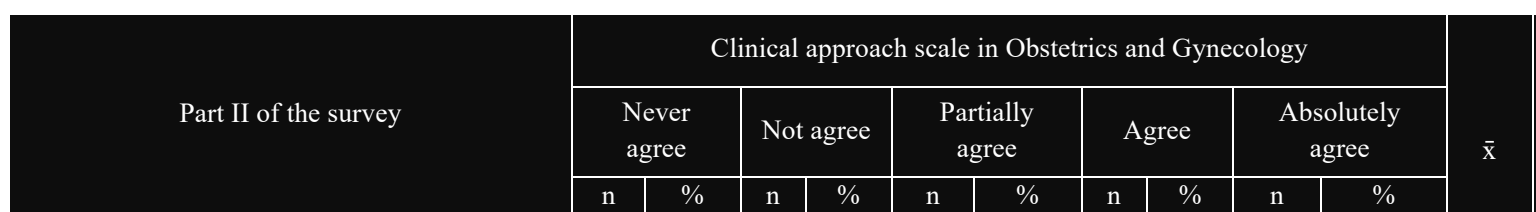

Clinical effect section

\begin{tabular}{l|l|l|l|l|l}
$\mathrm{n}$ & $\%$ & $\mathrm{n}$ & $\%$ & $\mathrm{n}$ & $\%$ \\
\hline
\end{tabular}

n $\%$

3.79

The number of patients admitted in the pandemic process changed

The number of patients admitted to the pandemic period has decreased significantly I use surgical mask and/or face shield during the outpatient examination

I use respiratory mask and/or face shield in the operating room

I feel uncomfortable because of being away from my routine program during the pandemic process

I ask questions about the coronavirus related symptoms while accepting cases in the

\begin{tabular}{|l|l|l|l|l|l|l|l|l|l|l|}
\hline 10 & 8.2 & 7 & 5.7 & 23 & 18.9 & 22 & 18.0 & 60 & 49.2 & 3.94 \\
\hline 12 & 9.8 & 13 & 10.7 & 17 & 13.9 & 29 & 23.8 & 51 & 41.8 & 3.77 \\
\hline 26 & 21.3 & 13 & 10.7 & 10 & 8.2 & 10 & 8.2 & 63 & 51.6 & 3.58 \\
\hline 16 & 13.1 & 14 & 11.5 & 9 & 7.4 & 13 & 10.7 & 70 & 57.4 & 3.87 \\
\hline 10 & 8.2 & 11 & 9.0 & 31 & 25.4 & 39 & 32.0 & 31 & 25.4 & 3.57 \\
\hline 10 & 8.2 & 9 & 7.4 & 15 & 12.3 & 24 & 19.7 & 64 & 52.5 & 4.00 \\
\hline
\end{tabular}

0.91

1.28

1.35

1.67

1.30 pandemic process

I receive a separate consent form related to Covid-19 from patients who are admitted to the hospital during the pandemic process; (yes $34.5 \%$ )

I want Covid-19 test in patients who are admitted to the hospital during the pandemic process (yes 3.3\%)

\section{Clinical functioning section}

I renewed my routine diagnosis and treatment practice in the light of current guidelines during the pandemic process

I think that the Covid-19 condition mostly affects the diagnosis and treatment method in the pandemic process

I only care for emergency cases during the pandemic process

I reduced the follow-up frequency of pregnant women with low risk

I reduced the follow-up frequency of pregnant women with high risk

I reduced the follow-up frequency of benign gynecological cases

I reduced the follow-up frequency of premalign/malign gynecological cases

Patients who have been given an outpatient appointment postpone their appointments

Patients who have been given a surgery date appointment delay their appointments

Patients requiring follow-up after treatment are not followed

\begin{tabular}{|c|c|c|c|c|c|c|c|c|c|c|c|}
\hline & & & & & & & & & & 3.15 & 0,64 \\
\hline 8 & 6.6 & 7 & 5.7 & 20 & 16.4 & 56 & 45.9 & 31 & 25.4 & 3.77 & 1.09 \\
\hline 5 & 4.1 & 10 & 8.2 & 35 & 28.7 & 42 & 34.4 & 30 & 24.6 & 3.67 & 1.06 \\
\hline 13 & 10.7 & 14 & 11.5 & 31 & 25.4 & 34 & 27.9 & 30 & 24.6 & 3.44 & 1.27 \\
\hline 7 & 5.7 & 11 & 9.0 & 24 & 19.7 & 45 & 36.9 & 35 & $28, .7$ & 3.73 & 1.14 \\
\hline 45 & 36.9 & 27 & 22.1 & 23 & 18.9 & 17 & 13.9 & 10 & 8.2 & 2.34 & 1.32 \\
\hline 6 & 4.9 & 4 & 3.3 & 19 & 15.6 & 47 & 38.5 & 46 & 37.7 & 4.00 & 1.05 \\
\hline 39 & 32.0 & 32 & 26.2 & 28 & 23.0 & 11 & 9.0 & 12 & 9.8 & 1.36 & 0.85 \\
\hline 12 & 9.8 & 24 & 19.7 & 50 & 41.0 & 27 & 22.1 & 9 & 7.4 & 2.97 & 1.06 \\
\hline 5 & 4.1 & 7 & 5.7 & 8 & 6.6 & 8 & 6.6 & 94 & 77.0 & 2.80 & 1.20 \\
\hline 19 & 15.6 & 31 & 25.4 & 41 & 33.6 & 17 & 13.9 & 14 & 11.5 & 2.42 & 1.14 \\
\hline & & & & & & & & & & 3.72 & 0.76 \\
\hline 7 & 5.7 & 18 & 14.8 & 32 & 26.2 & 34 & 27.9 & 31 & 25.4 & 3.52 & 1.18 \\
\hline 3 & 2.5 & 3 & 2.5 & 19 & 15.6 & 39 & 32.0 & 58 & 47.5 & 4.19 & 0.95 \\
\hline 2 & 1.6 & 9 & 7.4 & 38 & 31.1 & 41 & 33.6 & 32 & 26.2 & 3.75 & 0.98 \\
\hline 7 & 5.7 & 17 & 13.9 & 42 & 34.4 & 30 & 24.6 & 26 & 21.3 & 3.41 & 1.14 \\
\hline
\end{tabular}

I think that tele-congresses held during the pandemic process will be as common as classic-congresses

I think that tele-patient/physician interviews made during the pandemic process will be as common as classic-examination

Struggle and prevention section

I do not have a problem in terms of supplying protective equipment

I use protective equipment properly

I think we are successful as a health system about struggling pandemic

I think we are successful as a country about struggling pandemic

of the gynecological cases increases. Finally, there was a

In addition, a weak correlation was found between the clinical functioning and deferral status of the gynecological cases at $\mathrm{p}=0.01$ error level $(-0,278)$. In other words, as the effect of pandemic on clinical functioning increases, the delay linear moderate relationship between deferral status of the gynecological and obstetrical cases at $\mathrm{p}=0.01$ error level (0.405). With the postponement of the obstetrical cases, the probability of delaying gynecological cases increases. 
Table 3. The clinical urgency scale in obstetrics and gynecology

\begin{tabular}{|c|c|c|c|c|c|c|c|c|c|c|c|c|}
\hline \multirow[b]{2}{*}{ Part III of the survey } & \multicolumn{10}{|c|}{ Clinical urgency scale in obstetrics and gynecology } & \multirow[b]{2}{*}{$\overline{\mathrm{x}}$} & \multirow[b]{2}{*}{ SS } \\
\hline & \multicolumn{2}{|c|}{$\begin{array}{l}\text { Absolutely } \\
\text { deferable }\end{array}$} & \multicolumn{2}{|c|}{$\begin{array}{c}\text { Mostly } \\
\text { deferable }\end{array}$} & \multicolumn{2}{|c|}{$\begin{array}{l}\text { Partially } \\
\text { deferable }\end{array}$} & \multicolumn{2}{|c|}{$\begin{array}{l}\text { Mostly } \\
\text { urgent }\end{array}$} & \multicolumn{2}{|c|}{$\begin{array}{l}\text { Absolutely } \\
\text { urgent }\end{array}$} & & \\
\hline Obstetrics & & & & & & & & & & & 3.51 & 0.75 \\
\hline Hyperemesis gravidarum & 59 & 48.4 & 34 & 27.9 & 24 & 19.7 & 3 & 2.5 & 2 & 1.6 & 1.81 & 0.94 \\
\hline Abortusimminens & 32 & 26.2 & 40 & 32.8 & 24 & 19.7 & 12 & 9.8 & 14 & 11.5 & 2.47 & 1.29 \\
\hline Preterm birth & 4 & 3.3 & 12 & 9.8 & 28 & 23.0 & 27 & 22.1 & 51 & 41.8 & 3.89 & 1.15 \\
\hline $\begin{array}{l}\text { Preterm rupture of } \\
\text { membranes }\end{array}$ & 3 & 2.5 & 5 & 4.1 & 18 & 14.8 & 22 & 18.0 & 74 & 60.7 & 4.30 & 1.02 \\
\hline Gestational hypertension & 3 & 2.5 & 5 & 4.1 & 7 & 5.7 & 29 & 23.8 & 78 & 63.9 & 4.42 & 0.95 \\
\hline Gestational diabetes & 2 & 1.6 & 9 & 7.4 & 38 & 31.1 & 32 & 26.2 & 41 & 33.6 & 3.82 & 1.03 \\
\hline Noninvasive prenatal tests & 15 & 12.3 & 13 & 10.7 & 24 & 19.7 & 42 & 34.4 & 28 & 23.0 & 3.45 & 1.29 \\
\hline $\begin{array}{l}\text { Second trimester } \\
\text { sonography }\end{array}$ & 13 & 10.7 & 8 & 6.6 & 20 & 16.4 & 46 & 37.7 & 35 & 28.7 & 3.67 & 1.25 \\
\hline Invasive prenatal tests & 9 & 7.4 & 10 & 8.2 & 21 & 17.2 & 39 & 32.0 & 43 & 35.2 & 3.79 & 1.25 \\
\hline Gynecology & & & & & & & & & & & 2.39 & 0.71 \\
\hline Vaginal discharge & 80 & 65.6 & 24 & 19.7 & 17 & 13.9 & 1 & 0.8 & 0 & 0.0 & 1.50 & 0.76 \\
\hline Pelvic pain & 35 & 28.7 & 49 & 40.2 & 31 & 25.4 & 5 & 4.1 & 2 & 1.6 & 2.09 & 0.92 \\
\hline $\begin{array}{l}\text { Irregular menstrual } \\
\text { bleeding }\end{array}$ & 36 & 29.5 & 40 & 32.8 & 35 & 28.7 & 10 & 8.2 & 1 & 0.8 & 2.18 & 0.97 \\
\hline Heavy menstrual bleeding & 13 & 10.7 & 24 & 19.7 & 44 & 36.1 & 27 & 22.1 & 14 & 11.5 & 3.04 & 1.14 \\
\hline $\begin{array}{l}\text { Routine smear/HPV } \\
\text { scanning }\end{array}$ & 63 & 51.6 & 16 & 13.1 & 36 & 29.5 & 6 & 4.9 & 1 & 0.8 & 1.90 & 1.03 \\
\hline $\begin{array}{l}\text { Colposcopy/cervical } \\
\text { biopsy in CIN }\end{array}$ & 24 & 19.7 & 19 & 15.6 & 32 & 26.2 & 26 & 21.3 & 21 & 17.2 & 3.00 & 1.36 \\
\hline Diagnostic hysterescopy & 28 & 23.0 & 36 & 29.5 & 43 & 35.2 & 9 & 7.4 & 6 & 4.9 & 2.41 & 1.07 \\
\hline Operative hysterescopy & 17 & 13.9 & 24 & 19.7 & 43 & 35.2 & 26 & 21.3 & 12 & 9.8 & 2.93 & 1.16 \\
\hline Diagnostic laparoscopy & 47 & 38.5 & 36 & 29.5 & 29 & 23.8 & 6 & 4.9 & 4 & 3.3 & 2.04 & 1.05 \\
\hline Operative laparoscopy & 30 & 24.6 & 19 & 15.6 & 40 & 32.8 & 23 & 18.9 & 10 & 8.2 & 2.70 & 1.25 \\
\hline Gynecological cancers & 2 & 1.6 & 2 & 1.6 & 15 & 12.3 & 39 & 32.0 & 64 & 52.4 & 4.31 & 0.87 \\
\hline Infertility research & 80 & 65.6 & 31 & 25.4 & 6 & 4.9 & 3 & 2.5 & 2 & 1.6 & 1.49 & 0.83 \\
\hline Infertility therapy & 75 & 61.5 & 26 & 21.3 & 16 & 13.1 & 4 & 3.3 & 1 & 0.8 & 1.61 & 0.89 \\
\hline
\end{tabular}

Table 4. Correlation analysis between clinical approach scale and clinic urgency scale in obstetrics and gynecology

\begin{tabular}{|c|c|c|c|c|c|}
\hline & $\begin{array}{c}\text { Clinic approach } \\
\text { scale - Clinical } \\
\text { effect }\end{array}$ & $\begin{array}{l}\text { Clinic approach scale - } \\
\text { Clinical functioning }\end{array}$ & $\begin{array}{l}\text { Clinic approach scale - } \\
\text { Struggle and prevention }\end{array}$ & $\begin{array}{l}\text { Clinic urgency } \\
\text { scale- Obstetrics }\end{array}$ & $\begin{array}{c}\text { Clinic urgency } \\
\text { scale- Gynecology }\end{array}$ \\
\hline $\begin{array}{l}\text { Clinic approach scale - } \\
\text { Clinical effect }\end{array}$ & (5) & & & & \\
\hline $\begin{array}{l}\text { Clinic approach scale - } \\
\text { Clinical functioning }\end{array}$ & $.210(*)$ & 1 & & & \\
\hline $\begin{array}{l}\text { Clinic approach scale - } \\
\text { Struggle and prevention }\end{array}$ & .077 & .159 & 1 & & \\
\hline $\begin{array}{l}\text { Clinic urgency scale- } \\
\text { Obstetrics }\end{array}$ & .139 & -.018 & .015 & 1 & \\
\hline $\begin{array}{l}\text { Clinic urgency scale- } \\
\text { Gynecology }\end{array}$ & .035 & $-.278(* *)$ & -.072 & $.405(* *)$ & 1 \\
\hline
\end{tabular}

\section{Discussion}

There was considerable confusion regarding the clinical approaches in the early stage of the outbreak. However, at this stage, many associations have expressed their views on how clinical approaches can be applied in the pandemic process. In our study, we revealed that obstetrics and gynecology clinics are highly affected by the pandemic. Most of the authorities aim to reduce the clinical effect without disrupting clinical functioning. The current study has showed that the effect degree was $3.79,3.15,3.72$ respectively at clinical effect, clinical functioning and struggle and prevention.

In the study, it was stated that the number of patients who applied to the obstetrics and gynecology clinic during the pandemic process changed significantly (3.94). This condition is directly correlated with suggestions of WHO and CDC (12, 13); so, the patients in Turkey rely on cautions about decreasing contact and staying at home (8). When the physicians have been asked about the symptom questioning of every patient about COVID-19, mostly answered as symptom 
questioning of every patient have been done (4.0); but only $3.3 \%$ requested COVID-19 test in patients who needed hospitalization. That symptom questioning ratio is compatible with the suggestions of the societies. American Congress of Obstetricians and Gynaecologists (ACOG), The Royal College of Obstetricians and Gynaecologists (RCOG) and Society for Maternal Fetal Medicine (SMFM) suggest some patient acceptance charts, after the chart questioning, low risk population is accepted to make their examination in the routine clinical environment (14-16). Even it is mentioned, before application to hospitals, screening of the symptoms by telephone and then the scheduling of outpatient appointments can be done (17). In open-ended questions about the clinical effect, $34.5 \%$ of the doctors who stated that they routinely received a separate consent form from the patients for inpatient treatments for other health problems.

It was stated that physicians have greatly renewed their diagnosis and treatment practices in the light of current guidelines (3.77) and most physicians think that the COVID19 situation has a major influence on diagnosis and treatment management (3.67). It was concluded in the present study that, the physicians postponed the follow-up and treatment of low risk pregnancies (3.73) and benign gynecological diseases (4.00). But the physicians preferred to preserve the routine diagnosis and treatment algorithms of high-risk pregnancies (2.34) and gynecologic oncologic diseases (2.34). The physicians stated that also the patients preferred to postpone their outpatient (2.97) and surgery date appointments (2.80).

In open-ended questions about the clinical functioning, $50 \%$ of the physicians stated that online scientific congresses and $52.4 \%$ of the physicians stated that online therapies would become more widespread after the pandemic. SMFM declared that community mitigation efforts are important but local practice and population factors and the resources like tele-health (including telephone with other remote services) is the critical point to practice (16). Also, it is important to categorize the cases as high-risk or low-risk and according to the risk assessment to decide urgent/semi-urgent/deferrable or non-deferrable cases. The tele-health and other remote services can come into question after the clinicians experienced and the societies definitely decided which cases are deferrable or non-deferrable.

The clinical urgency scale was designed to answer which obstetrical and gynecological conditions that described as deferrable, semi-urgent or urgent. Most of the obstetrical conditions had been found as non-deferrable and so urgent by the clinicians (3.51); but only hyperemesis gravidarum (1.81) and abortus imminens (2.47) was found to be deferrable regardless of time. Because hyperemesis gravidarum and abortus imminens require less hospitalization and these conditions do not cause severe obstetrical complications generally. Currently, there is no evidence to suggest that
COVID-19 causes developmental problems or causes miscarriage. With regard to vertical transmission (transmission from woman to baby antenatal or intrapartum), emerging evidence now suggests that vertical transmission may be possible $(18,19)$. Preterm birth (3.89) and preterm rupture of membranes (4.30) were found to be urgent obstetrical complications so physicians considered both conditions to be non-deferrable. The clinicians have evaluated gestational diabetes (3.82) and gestational hypertension (4.42) as emergency obstetrical conditions which cannot be deferrable. The clinicians care about high risk pregnancies such as preterm birth, preterm rupture of membranes, gestational diabetes and gestational hypertension- by considering both maternal and fetal morbidity/mortality, regardless of pandemic and maintain their routine practices. The risk of an asymptomatic pregnant progressing to severe COVID-19 disease is unknown, but is usually thought to be equivalent to that of health- and age-matched women. But if there is comorbidity accompanying pregnancy like gestational diabetes or hypertension disorders, that may contribute to increased risk related with COVID-19 $(20,21)$.

And clinicians stated that noninvasive prenatal tests (such as double, triple and quadruple tests) (3.45) can be postponed for a while. However, the clinicians stated that, second trimester ultrasound (3.67) and invasive prenatal tests (such as amniocentesis, chorionic villus sampling and cordocentesis) (3.79) are urgent and so non-deferrable situations for the prenatal diagnosis. According to the clinicians, while noninvasive prenatal tests have been found to be deferrable for a while due to their wide application time ranges and interchangeability, invasive prenatal tests and second trimester ultrasound cannot be postponed because of their limited application time intervals. The invasive fetal procedures in which the fetus/mother benefit ratio is high and the procedure's theoretical risk of vertical transmission is low or moderate, like chorionic villus sampling, amniocentesis, fetal blood transfusion, thoracoamniotic shunting, laser for twin-to-twin transfusion syndrome, spina bifida closure, are considered as safe procedures and can be done with the COVID-19 risk assessment of the pregnant (22).

The International Fetal Medicine and Surgery Society (IFMSS) and other societies have published guidelines for routine prenatal care and screening during COVID-19 pandemic (20). Routine antenatal visits can be spaced out, after first prenatal visit detecting the pregnancy and special risk factors, Down syndrome screening and other virtual ultrasound scan may be delayed until 12-13 week of pregnancy, blood test for routine controls can be taken together with noninvasive prenatal testing. Detailed anomaly ultrasound scanning should be delayed until 20-22 weeks (22).

The clinicians have evaluated the gynecological conditions to be deferrable either regardless of time or for a 
while (2.39). As a result of the research, frequent gynecological symptoms such as vaginal discharge (1.50) and pelvic pain (2.09) were seen to be deferrable regardless of time. And irregular menstrual bleeding (2.18) was found to be deferrable regardless of time, while heavy menstrual bleeding (3.04) was found to be deferrable for a while but not urgent. The important point in irregular menstrual bleeding is to diagnose important diseases such as endometrial cancer and the clinicians think that the reasonable delay in the pandemic process is not important. However, increased morbidity in heavy menstrual bleeding is thought to be more important than the delay in cancer diagnosis. Therefore, the clinicians think that, while irregular menstrual bleeding can be postponed regardless of time, heavy menstrual bleeding can be delayed for a while. Irregular uterine bleeding is generally associated with decreased ovarian function. However, obese and late reproductive aged women have higher risk for endometrial cancer. RCOG, British Society for Gynaecological Endoscopy (BSGE) and British Gynaecological Cancer Society (BGCS) concluded that women at high risk for endometrial cancer must be screened by physicians as soon as possible (23). In our study, we stated that the number of patients admitted to the hospital during the pandemic period decreased significantly. Complaints like vaginal discharge, pelvic pain, irregular menstrual bleeding and demands of patients like routine smear screening, infertility treatments and infertility search constitute the main patient burden of gynecology practice in Turkey. That's why we think, the decrease in the number of patients depends on delaying the appointments of the patients who plan to apply to the hospital based on these several complaints.

According to the physicians, routine smear and HPV scanning (1.90) are mostly deferrable regardless of time. But colposcopy/cervical biopsy in cervical preinvasive lesions (3.00) was found to be deferrable for a while, not urgent. According to American Society for Colposcopy and Cervical Pathology (ASCCP), individuals with low-grade cervical cancer screening tests may have postponement for 6-12 months and individuals with high-grade cervical screening tests should have diagnostic evaluation within 3 months (24). This information is also correlated with our study results. While diagnostic hysteroscopy /laparoscopy procedures (2.41, 2.04) for gynecological diseases were founded to be deferrable regardless of time, operative hysteroscopy /laparoscopy procedures $(2.93,2.70)$ were found to be deferrable for a while. Generally according to our study, while the procedures used in the diagnosis of gynecological diseases can be postponed regardless of time, the procedures for treatment have only been postponed for a while.

In the current study, the only condition among gynecological causes, which was founded to be urgent and cannot be deferrable, was gynecological cancers (4.31). Even in the pandemic process, the delay in cancer treatment was found unacceptable by clinicians. But at that point, gynecologic and other cancer associations were more cautious. They evaluated the cancers as low-risk, high-risk and advanced disease and suggested degreed and softened therapy strategies. For example, in the low-risk endometrial cancer, they suggested non-surgical options like hormonal intrauterine devices. In ovarian cancer, in patients who have already taken neoadjuvant chemotherapy, extending the chemotherapy time to six cycles, rather than three, and then planning the interval cytoreductive surgery (24).

According to the clinicians both infertility research and infertility treatments were found to be deferrable regardless of time $(1.49,1.61)$. International Federation of Fertility Societies (IFFS) has conducted an online survey with respondents from 93 countries. The study showed that the fertility treatment was not considered as an essential health service during the pandemic. Most of the countries modified their policies about fertility treatment; and many artificial reproductive technologies (ART) center had been closed or presented limited opportunities for some special conditions (25). Unlike these considerations, according to the document prepared by the European Society of Human Reproduction and Embryology (ESHRE) COVID-19 working group, while our internet survey was continuing, as the COVID-19 pandemic is getting stabilized, the return to normal life will also need to restart of ART treatments. They say that infertility is an important disease and the spreading of the pandemic is decreasing, all ART treatments can be restarted for any clinical indication, in line with local regulations (26).

In our study, we investigated the effects of pandemic in obstetrics and gynecology clinics. We think that the study will help in determining our approach to obstetrical and gynecological cases in the future. The effects of a pandemic on health systems should be examined on the basis of each unit from smallest to biggest: clinic, hospital, city, country. Other studies together with this study, investigating delay times or urgency categorization in diagnosis and treatments of obstetrical and gynecological diseases will give directions to the clinics and health system managers. Scenarios should be made patient-centered without neglecting the burden and possible damages on healthcare professionals.

\section{Acknowledgments}

The authors would like to thank all the obstetricians and gynecologists who offered their time and energy to participate in the survey.

\section{Conflict of interest}

The authors certify that they have no financial or nonfinancial interest in the subject matter or materials discussed in this manuscript.

\section{References}

1. Zhu N, Zhang D, Wang W, Li X, Yang B, Song J, et al; China Novel Coronavirus Investigating and Research Team. A Novel Coronavirus from Patients with Pneumonia in China, 2019. N Engl J Med. 2020 Feb 20;382(8):727-733. doi: 


\subsection{6/NEJMoa2001017.}

2. Huang $\mathrm{C}$, Wang $\mathrm{Y}, \mathrm{Li} \mathrm{X}$, Ren $\mathrm{L}$, Zhao J, Hu Y, et al. Clinical features of patients infected with 2019 novel coronavirus in Wuhan, China. Lancet. 2020 Feb 15;395(10223):497-506. doi: 10.1016/S0140-6736(20)30183-5.

3. World Health Organization (WHO), Coronavirus disease (COVID-19) pandemic [Internet]. 2020 [updated 2020 March 11; cited 2021 March 1]. Available from: https://www.who.int/emergencies/diseases/novel-coronavirus2019

4. Habibzadeh P, Stoneman EK. The Novel Coronavirus: A Bird's Eye View. Int J Occup Environ Med. 2020 Apr;11(2):65-71. doi: 10.15171/ijoem.2020.1921.

5. Fan Y, Zhao K, Shi ZL, Zhou P. Bat Coronaviruses in China. Viruses. 2019 Mar 2;11(3):210. doi: 10.3390/v11030210.

6. International Committee on Taxonomy of Viruses, Taxonomy history: Orthocoronavirinae [Internet]. 2020 [updated 2020 January 1; cited 2021 March 1]. Available from: https://talk.ictvonline.org//taxonomy/p/taxonomyhistory?taxnode_id $=201851847$

7. Interactive visualization of the exponential spread of COVID-19, Data Repository by Johns Hopkins CSSE [Internet]. 2020 [updated 2020 March 11; cited 2021 March 1]. Available from: https://91divoc.com/pages/COVID-visualization/

8. Turkey Ministry of Health, Coronavirus data [Internet]. 2020 [updated 2020 March 11; cited 2021 March 1]. Available from: https://COVID19.saglik.gov.tr/

9. The Centers for Medicare \& Medicaid Services (CMS), Recommendations on adult elective surgeries, non-essential medical, surgical, and dental procedures during COVID-19 response [Internet]. 2020 [updated 2020 March 18; cited 2021 March 1]. Available from: https://www.cms.gov/newsroom/press-releases/cmsreleasesrecommendations-adult-elective-surgeries-non-essentialmedical-surgicaland- dental.

10. Ambulatory Surgery Center Association (ASCA), State guidance on elective surgeries [Internet]. 2020 [updated 2020 April 20; cited 2021 March 1]. Available from: https://www.ascassociation.org/COVID-19-state.

11. Stephens AJ, Barton JR, Bentum NA, Blackwell SC, Sibai BM. General Guidelines in the Management of an Obstetrical Patient on the Labor and Delivery Unit during the COVID-19 Pandemic. Am J Perinatol. 2020 Jun;37(8):829-836. doi: 10.1055/s-00401710308.

12. World Health Organization (WHO), Country\&Techical Guidance [Internet]. 2021 [updated 2021 February 10; cited 2021 March 1]. Available from: https://www.who.int/emergencies/diseases/novel-coronavirus2019/technical-guidance/infection-prevention-and-control

13. Centers for Disease Control and Prevention (CDC), Coronavirus Disease 2019 (COVID-19) [Internet]. 2021 [updated 2021 March 8; cited 2021 March 11]. Available from: https://www.cdc.gov/coronavirus/2019-ncov/prevent-gettingsick/prevention.html

14. American Congress of Obstetricians and Gynaecologists (ACOG). Outpatient Assessment and Management for Pregnant Women With Suspected or Confirmed Novel Coronavirus (COVID-19) [Internet]. 2020 [updated 2020 December 14; cited 2021 March 1]. Available from:https://www.acog.org/clinical/clinical-guidance/practiceadvisory/articles/2020/03/novel-coronavirus-2019
15. RCOG, BSGE and BGCS joint, Guidance for the management of abnormal uterine bleeding in the evolving Coronavirus (COVID19) pandemic. [Internet]. 2020 [updated 2020 March 31; cited 2021 March 1]. Available from: https://mk0britishsociep8d9m.kinstacdn.com/wpcontent/uploads/2020/03/Joint-RCOG-BSGE-BGCS-guidancefor-management-of-abnormal-uterine-bleeding-AUB-in-theevolving-Coronavirus-COVID-19-pandemic-300320-2.pdf

16. The Society for Maternal-Fetal Medicine (SMFM), Coronavirus (COVID-19) and Pregnancy: What Maternal-Fetal Medicine Subspecialists Need To Know [Internet]. 2020 [updated 2020 March 11; cited 2021 March 1]. Available from: https://s3.amazonaws.com/cdn.smfm.org/media/2262/COVID19 PDF.pdf

17. Jamieson DJ, Steinberg JP, Martinello RA, Perl TM, Rasmussen SA. Obstetricians on the Coronavirus Disease 2019 (COVID-19) Front Lines and the Confusing World of Personal Protective Equipment. Obstet Gynecol. 2020 Jun;135(6):1257-1263. doi: 10.1097/AOG.0000000000003919.

18. Dong L, Tian J, He S, Zhu C, Wang J, Liu C, et al. Possible Vertical Transmission of SARS-CoV-2 From an Infected Mother to Her Newborn. JAMA. 2020 May 12;323(18):1846-1848. doi: 10.1001/jama.2020.4621.

19. Chen H, Guo J, Wang C, Luo F, Yu X, Zhang W, et al. Clinical characteristics, and intrauterine vertical transmission potential of COVID-19 infection in nine pregnant women: a retrospective review of medical records. Lancet. 2020 Mar 7;395(10226):809815. doi: 10.1016/S0140-6736(20)30360-3.

20. Poon LC, Yang H, Lee JCS, Copel JA, Leung TY, Zhang Y, et al. ISUOG Interim Guidance on 2019 novel coronavirus infection during pregnancy and puerperium: information for healthcare professionals. Ultrasound Obstet Gynecol. 2020 May;55(5):700-708. doi: 10.1002/uog.22013.

21. Zhang L, Jiang Y, Wei M, Cheng BH, Zhou XC, Li J, et al. [Analysis of the pregnancy outcomes in pregnant women with COVID-19 in Hubei Province]. Zhonghua Fu Chan Ke Za Zhi. 2020 Mar 25;55(3):166-171. Chinese. doi: 10.3760/cma.j.cn112141-20200218-00111.

22. Deprest J, Choolani M, Chervenak F, Farmer D, Lagrou K, Lopriore E, et al. Fetal Diagnosis and Therapy during the COVID-19 Pandemic: Guidance on Behalf of the International Fetal Medicine and Surgery Society. Fetal Diagn Ther. 2020;47(9):689-698. doi: 10.1159/000508254.

23. RCOG, BSGE and BGCS joint, Guidance for the management of abnormal uterine bleeding in the evolving Coronavirus (COVID19) pandemic. [Internet]. 2020 [updated 2020 March 31; cited 2021 March 1]. Available from: https://mk0britishsociep8d9m.kinstacdn.com/wpcontent/uploads/2020/03/Joint-RCOG-BSGE-BGCS-guidancefor-management-of-abnormal-uterine-bleeding-AUB-in-theevolving-Coronavirus-COVID-19-pandemic-300320-2.pdf

24. Ramirez PT, Chiva L, Eriksson AGZ, Frumovitz M, Fagotti A, Gonzalez Martin A, et al. COVID-19 Global Pandemic: Options for Management of Gynecologic Cancers. Int J Gynecol Cancer. 2020 May;30(5):561-563. doi: 10.1136/ijgc-2020-001419.

25. International Federation of Fertility Societies (IFFS), COVID-19 Task Force Statements [Internet]. 2020 [updated 2020 December 16; cited 2021 March 1]. Available from: https://www.iffsreproduction.org/page/COVIDStatements

26. European Society of Human Reproduction and Embryology (ESHRE), COVID-19 and ART [Internet]. 2020 [updated 2020 November 26; cited 2021 March 1]. Available from: https://www.eshre.eu/Home/COVID19WG 